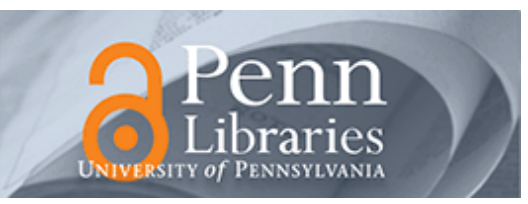

University of Pennsylvania

ScholarlyCommons

\title{
State Behavioral Scale (SBS) A Sedation Assessment Instrument for Infants and Young Children Supported on Mechanical Ventilation
}

Martha A. Q. Curley

University of Pennsylvania, curley@nursing.upenn.edu

Sion Kim Harris

Karen A. Fraser

Rita A. Johnson

John H. Arnold

Follow this and additional works at: https://repository.upenn.edu/nrs

Part of the Critical Care Nursing Commons, and the Pediatric Nursing Commons

\section{Recommended Citation}

Curley, M. A., Harris, S. K., Fraser, K. A., Johnson, R. A., \& Arnold, J. H. (2006). State Behavioral Scale (SBS) A Sedation Assessment Instrument for Infants and Young Children Supported on Mechanical Ventilation. Pediatric Critical Care Medicine, 7 (2), 107-114. http://dx.doi.org/10.1097/01.PCC.0000200955.40962.38 


\title{
State Behavioral Scale (SBS) A Sedation Assessment Instrument for Infants and Young Children Supported on Mechanical Ventilation
}

\author{
Abstract \\ Objective: To develop and test the reliability and validity of the State Behavioral Scale for use in describing \\ sedation/agitation levels in young intubated patients supported on mechanical ventilation. \\ Design: In this prospective, psychometric evaluation, pairs of trained pediatric critical care nurse \\ evaluators simultaneously and independently assessed a convenience sample of pediatric intensive care \\ unit patients along eight state/behavioral dimensions and a numeric rating scale (NRS) of 0 (extremely \\ sedated) to 10 (extremely agitated). The eight dimensions were derived from the sedation/agitation \\ literature and expert opinion and included respiratory drive, response to ventilation, coughing, best \\ response to stimulation, attentiveness to careprovider, tolerance to care, consolability, and movement \\ after consoled, each with 3-5 levels.
}

Setting: An 18-bed pediatric medical-surgical intensive care unit and 26-bed pediatric cardiovascular intensive care unit in a university-affiliated academic children's hospital.

Patients: A total of 91 intubated mechanically ventilated patients 6 wks to 6 yrs of age provided a median of two observations (interquartile range, 1-3) for a total of 198 sets of observations. Excluded were postoperative patients or those receiving neuromuscular blockade.

Interventions: Patients were observed for $1 \mathrm{~min}$, and then incremental levels of stimulation were applied until patient response. After 2 mins of consoling, the state behavioral assessment and NRS were completed.

Measurements: Weighted kappa and intraclass coefficients were generated to assess interrater reliability of the eight dimension and NRS ratings. Distinct state behavior profiles were empirically identified from the dimension ratings using hierarchical cluster analysis using a squared Euclidean distance measure and between-groups linkage. Construct validity of these profiles was assessed by comparing group mean NRS scores using one-way analysis of variance.

Main Results: Weighted kappa scores for all 198 dimension ratings ranged from .44 to .76, indicating moderate to good interrater reliability. The intraclass coefficient of .79 was high for NRS ratings. Cluster analysis revealed five distinct state profiles, with mean NRS ratings of $1.1,2.5,4.0,5.3$, and 7.6 , all of which differed significantly from each other $(F=75.8, p<.001)$, supporting the profiles' construct validity.

Conclusions: Based on empirically derived state behavior profiles, we have constructed the State Behavioral Scale to allow systematic description of the sedation-agitation continuum in young pediatric patients supported on mechanical ventilation. Further studies including prospective validation and describing the effect of State Behavioral Scale implementation on clinical outcomes, including the quality of sedation and length of mechanical ventilation, are warranted.

\section{Keywords}

sedation, agitation, pediatric intensive care, child, nursing assessment

Disciplines

Critical Care Nursing | Medicine and Health Sciences | Nursing | Pediatric Nursing 
Published in final edited form as:

Pediatr Crit Care Med. 2006 March ; 7(2): 107-114.

\title{
State Behavioral Scale (SBS) A Sedation Assessment Instrument for Infants and Young Children Supported on Mechanical Ventilation
}

\author{
Martha A.Q. Curley, RN, PhD, FAAN, Sion Kim Harris, PhD, Karen A. Fraser, RN, Rita A. \\ Johnson, RN, BSN, and John H. Arnold, MD \\ Critical Care and Cardiovascular Program \\ Clinical Research Program \\ Clinical Research Center \\ Medical-Surgical Intensive Care Unit \\ Children's Hospital Boston, USA
}

\section{Abstract}

Objective-To develop and test the reliability and validity of the State Behavioral Scale (SBS) for use in describing sedation/agitation levels in young intubated patients supported on mechanical ventilation.

Design-Prospective, psychometric evaluation. Pairs of trained pediatric critical care nurse evaluators simultaneously and independently assessed a convenience sample of pediatric ICU patients along eight state/behavioral dimensions and a Numeric Rating Scale (NRS) of 0 (extremely sedated) to 10 (extremely agitated). The eight dimensions were derived from the sedation/agitation literature and expert opinion and included respiratory drive, response to ventilation, coughing, best response to stimulation, attentiveness to care provider, tolerance to care, consolability, and movement after consoled, each with 3-5 levels.

Setting-18-bed Pediatric Medical-Surgical ICU and 26-bed Pediatric Cardiovascular ICU in a university-affiliated academic children's hospital.

Patients-Ninety-one intubated mechanically ventilated patients $6 \mathrm{wks}$ to 6 years of age provided a median of 2 observations (IQR: 1-3) for a total of 198 sets of observations. Excluded were postoperative patients or those receiving neuromuscular blockade.

Interventions-Patients were observed for $1 \mathrm{~min}$ then incremental levels of stimulation were applied until patient response. After 2 minutes of consoling, the state behavioral assessment and NRS were completed.

Measurements-Weighted kappa and intra-class coefficients (ICC) were generated to assess interrater reliability of the eight dimension and NRS ratings. Distinct state behavior profiles were empirically identified from the dimension ratings using hierarchical cluster analysis using a squared Euclidean distance measure and between-groups linkage. Construct validity of these profiles was assessed by comparing group mean NRS scores using one-way analysis of variance.

Corresponding Author: Martha A.Q. Curley, R.N., PhD; Children's Hospital Boston; Critical Care and Cardiovascular Program; Farley 559; 300 Longwood Ave; Boston, MA 02115; Office: 617-355-6886; Fax: 617-730-0126; Martha.Curley@ Childrens.Harvard.edu.

Funding: NIH/NICHD 5R21HD045020-02; GCRC MO1-RR02172

the authors have no financial interests to disclose. 
Main Results-Weighted kappa scores for all 198 dimension ratings ranged from .44 to .76 indicating moderate to good inter-rater reliability. The ICC of .79 was high for NRS ratings. Cluster analysis revealed 5 distinct state profiles with mean NRS ratings of 1.1, 2.5, 4.0, 5.3, and 7.6, all of which differed significantly from each other $(\mathrm{F}=75.8, \mathrm{p}<0.001)$, supporting the profiles' construct validity.

Conclusions-Based on empirically derived state behavior profiles, we have constructed the SBS to allow systematic description of the sedation-agitation continuum in young pediatric patients supported on mechanical ventilation. Further studies including prospective validation and describing the effect of SBS implementation on clinical outcomes including the quality of sedation and length of mechanical ventilation are warranted.

\section{Keywords}

sedation; agitation; pediatric intensive care; child; nursing assessment

Ensuring the comfort of critically ill infants and children is integral to the practice of pediatric critical care. Humane pediatric intensive care often includes the administration of sedatives, once pain, physiologic imbalance and environmental stressors have been addressed.[1] Over $90 \%$ of infants and children supported on mechanical ventilation receive some form of sedative therapy. [2] Sedation in this patient population is required for anxiolysis, amnesia, facilitation of care, patient safety in avoidance of adverse events and for decreasing oxygen consumption. For most young patients supported on mechanical ventilation, the goal of sedation is to attain a calm but responsive state $[2,3]$ that protects the young patient from self-harm. Inadequate sedation is associated with potentially dangerous complications such as unplanned endotracheal extubation. [4] High-dose, long-term, and continuous intravenous sedation has been associated with prolonged weaning from mechanical ventilation and/or withdrawal syndrome. [5-7] Therefore, insufficient or excessive sedation is likely to add to the personal and financial burden of intensive care.

Variability complicates the use of sedation in the pediatric intensive care unit (PICU) setting. First, a patient's sedative needs vary depending on the nature and course of their illness, drug interaction with concomitant therapies, and their response to therapy. [8,9] Some patients require deep sedation to tolerate synchronous modes of mechanical ventilation while others appear comfortable with light sedation even when supported on unconventional modes of ventilatory support. [10] Next, from a systems perspective, multidisciplinary staff with varying levels of expertise change several times over the working day. This means that patients are exposed to multiple subjective assessments of their sedation requirements, by several staff members, which may result in patients receiving varying dosages of sedation depending upon who performed the assessment. [11,12]

Valid and reliable tools that standardize the description of a pediatric patient's behavioral state while supported on mechanical ventilation would enhance systematic assessment and documentation of a patient's response to sedation, allow patient-specific alterations in the therapeutic regimen, and help avoid insufficient or excessive sedative use. [13,14] Such an assessment tool would enhance interdisciplinary agreement on the desired level of sedation, provide a foundation for the development of guidelines that would decrease unnecessary variation in the care [15-17] and permit objective study of the pharmacodynamics of sedative agents in the pediatric population. [18] From a research perspective, Kollef and colleagues [5] suggest that sedation practices should be standardized in any investigation employing the duration of mechanical ventilation as an outcome variable.

While desirable, tools assessing the sedation-agitation continuum in the pediatric patient have not been adequately tested or have conceptual flaws. Specifically, the psychometrics of the 
Ramsay scale, [19] an often cited sedation scale used in the adult population, has never been evaluated in an ICU setting. In addition, Ramsay's 6 levels of sedation are neither mutually exclusive nor clearly defined. [20] The COMFORT scale, [14,21] the most commonly used tool in the pediatric population, [12] was designed to assess distress in ventilated children but distress was operationalized to include the constructs of both pain and agitation. Noting that the eight dimensions of the COMFORT scale are often included in other pain instruments, van Dijk and others [22] supported the use of the COMFORT scale to assess postoperative pain in infants. From a clinical perspective, separate valid and reliable pain and agitation assessment tools would allow more targeted therapeutic management. [23]

The purpose of this study was to empirically construct and demonstrate preliminary construct validity and inter-rater reliability of a pediatric sedation assessment scale, the State Behavioral Scale (SBS), for use in young critically ill pediatric patients supported on mechanical ventilation.

\section{MATERIALS AND METHODS}

\section{Data Collection Instrument}

A state behavioral assessment tool was derived from our previous work describing pediatric ICU nurses' descriptions of agitation, [24] the literature on sedation tools used in the adult population, [25-27] and expert opinion from a pediatric anesthesiologist and pediatric critical care clinical nurse specialist. Two adult ICU sedation scales, the Sedation-Agitation Scale (SAS) [25] and its derivative, the Motor Activity Assessment Scale (MAAS) [27,28] served as templates. As presented in Figure 1, we retained descriptors that could be evaluated in a cognitively immature patient population and added several descriptors important to the care of young patents supported on mechanical ventilation. Our tool included ratings along the following 8 dimensions: respiratory drive, response to ventilation, coughing, best response to stimulation, attentiveness to care provider, tolerance to care, consolability, and movement after consoled. Each dimension contained 3-6 levels that incrementally described the sedationagitation continuum.

Operational definitions included the following: Sedation, a calm tranquil state that allays anxiety and excitement; Agitation, excitement accompanied by increased motor activity; Attention, the ability to open eyes and notice surroundings; Response, the ability to open eyes, or raise eyebrows, or turn head toward stimulus or move limbs; Distress, sudden increase in heart rate or blood pressure, and or a decrease in $\mathrm{SpO} 2$, or increase in movement. The 0-10 Numeric Rating Scale (NRS) with 0 equal to "extremely sedated" and 10 equal to "extremely agitated" served as a reference standard. We did not include changes in heart rate and blood pressure as distinct dimensions in the state behavioral assessment because of consistently low sensitivity and specificity in predicting agitation. [21,24,29] We also did not include the patient's ability to communicate, follow commands, or attempts to sit or climb out of bed because these items are not consistently developmentally appropriate across the 6 week to 6 year age group.

\section{Patient Sample}

Between 2000 and 2004 we enrolled a convenience sample of patients, 6 weeks to 6 years of age, who were intubated and mechanically ventilated in either the Medical-Surgical ICU or Cardiovascular ICU in a university-affiliated academic children's hospital in the Northeast. Enrollment was stratified in 3 age groups ( 6 weeks to 1 year, 1 to 3 years and 3 to 6 years) to ensure an almost equal distribution of age within our sample. We excluded patients receiving neuromuscular blockade; post-operative patients; patients assessed to be in pain by their bedside nurse, patients who were considered physiologically unstable (those experiencing any 
increase in ventilator or vasopressors support in the previous 2 hours), and patients at risk for opioid withdrawal. Exclusion criteria were selected to eliminate patients incapable of providing behavioral clues and patients more likely to provide pain-related clues. Data collection did not alter in any way the current practice and/or the administration of sedatives. The study was approved by the Institutional Review Board and need for informed consent was waived because data were de-identified, considered to be low-risk and were collected during routine patient care.

\section{Data Collection}

A pair of trained pediatric critical care nurse evaluators simultaneously and independently conducted state behavioral assessments of each intubated, mechanically-ventilated pediatric patient in the sample. As part of their training prior to study implementation, a total of five critical care nurses were instructed on the use of the state behavioral assessment tool and NRS over the study period. After instruction, each nurse conducted five concurrent assessments per protocol with the principal investigator. The group then discussed their assessments and reached consensus on the best score within each dimension of the state behavioral assessment and NRS. Data collection commenced when the nurse raters agreed that they had reached a common understanding of the 8 state behavioral dimensions and the NRS and there was $95 \%$ agreement between the critical care nurse rater and principal investigator with disagreements not crossing more than one level in any dimension. Training data were not included in the final analyses.

Patients were enrolled as soon as possible after meeting criteria and were assessed daily for a maximum of 6 days. Prior to data collection, patients were presumed to be supported on appropriate ventilator settings. Data collection was conducted at a time when the bedside nurse was completing planned cares when two evaluators were available. If endotracheal extubation was planned, the patient was assessed just prior to the procedure.

First, patients were observed undisturbed for 1 minute. Second, the patient's nurse provided progressive stimuli, as necessary, to elicit a patient's response. Specifically, the nurse first spoke the patient's name using a calm voice, then, if there was no response, spoke the patient's name and gently touched the patient's body. If there was still no response, the patient's response to a planned noxious stimulus was assessed such as endotracheal suctioning or less than 5 seconds of nail bed pressure. Finally, the patient was repositioned, then consoled by the nurse and/or parent. After 2 minutes of consoling, evaluators completed the state behavioral assessment and gave a NRS rating. In evaluating the coughing dimension, the evaluator was allowed to query the bedside nurse about this dimension if a suctioning procedure was not observed. In addition to the behavioral ratings, demographic data, including age, gender, admission functional health, [30] admission PRISM III [31] and the use of mechanical ventilation and sedative use at the time of assessment were recorded.

\section{Statistical Analysis}

We generated descriptive statistics (means and standard deviations, medians and interquartile ranges, response proportions) on sample patient demographic characteristics including age, sex, race/ethnic group, primary and secondary diagnoses, cerebral and overall performance, and risk of mortality. We assigned numeric codes to each level of each state behavioral dimension for analyses, with 1 for the first level, and a high of 3 to 6 depending on the number of levels within a dimension. After reviewing frequency distributions, the respiratory drive and response to ventilation dimensions were collapsed into one dimension for subsequent analyses. The dimensions were collapsed because few patients exhibited, under respiratory drive, spontaneous but ineffective exhaled tidal volume or, under response to ventilation, unsynchronized with mechanical ventilation compromising oxygenation and ventilation. 
Inter-rater agreement for the 7 dimension ratings, consisting of ordinal data, was assessed using weighted kappa coefficients generated with PROC FREQ in SAS®. [32] We examined interrater agreement on the NRS rating, a continuous variable, with intraclass correlation coefficients generated in SPSS 12.0 using a one-way random effects model. We analyzed interrater reliability using all available paired ratings, which included multiple rating occurrences for some patients. Since there may have been intra-cluster correlation among multiple ratings of the same patient, we also conducted these analyses using only the first rating of each patient, as well as a randomly-selected single rating for each patient. In order to explore whether interrater agreement varied by patient age group, all inter-rater reliability analyses were stratified by the 3 patient age groups.

To identify distinct state behavior profiles based on dimension ratings, we conducted hierarchical cluster analysis using a squared Euclidean distance measure to assess similarity/ dissimilarity across variables, and between-groups linkage method for combining clusters. We ran the cluster analysis using data from Rater 1 only, Rater 2 only, and data averaged across the two raters. In addition, we conducted these analyses using all rating occurrences, as well as using only data from a randomly-selected single rating for each patient. Random selection of a single rating per patient was deemed preferable to using the first rating for each patient in these analyses since the first ratings tended to reflect more sedated states compared to subsequent ratings. Patients were generally more sedated immediately following intubation.

Since the 7 dimensions had differing response scale ranges, we ran the cluster analyses using standardized scores, where item scores were converted into z-scores. We chose the number of clusters by examining the agglomeration schedule and identifying the "elbow" in the curve of the distance measure across the cluster-joining steps (the point where the distance coefficient made a sudden jump in size). While this method of identifying the number of clusters indicated that there were likely to be 5 clusters or state-behavior profiles, we evaluated 3, 4, and 5 cluster solutions in subsequent analyses, in order to further determine the appropriateness of the 5-

cluster solution. After examining the median scores for each of the 7 SBS dimensions across the clusters, we determined that the 5 -cluster solution was appropriate, with the 5 groups showing distinct profiles of scores across the 7 state dimensions. To assess discriminant validity of the profiles, we used a one-way analysis of variance (ANOVA), with a post-hoc Tukey HSD test, to compare mean scores on the NRS variable across the 5 cluster groups. A two-sided pvalue of less than 0.05 indicated statistical significance. All cluster and mean score comparison analyses were performed with SPSS 12.0 software (Chicago, IL ).

Specific information needed (frequency distributions and correlations between raters) to perform power calculations for kappa coefficients was not known, leading to the need for preliminary data to be collected through this study. However, cross-sectional analyses on 90 subjects provides $82 \%$ power to detect inter-rater correlations of 0.30 and $98 \%$ power to detect correlations of 0.40 . Thus, we anticipated that our sample size of 90 subjects should be sufficient to detect moderate to high correlations and kappa coefficients and would provide enough pilot data for us to develop appropriate follow-up studies.

\section{RESULTS}

Ninety-one patients were enrolled. Patient demographic data are presented in Table 1. Most patients were cognitively and functionally normal for age. [30] The majority of the 91 patients $(\mathrm{N}=57 ; 63 \%)$ were intubated and mechanically ventilated for pulmonary parenchymal disease, with the rest having airways disease. Although conventional methods were used to ventilate most patients, 9\% (N=8) were supported on high frequency oscillatory ventilation (HFOV) and 3\% were supported on extracorporal membrane oxygenation (ECMO). Mortality rate was $13 \%$. Almost all (95\%) of the patients were receiving sedation. The most prevalent sedation 
plan $(73 \%)$ included a combination of opioids and benzodiazepines. Pairs of nurse evaluators assessed the 91 patients during 198 rating occurrences (396 total observations). Most patients provided one (46\%) or two (23\%) sets of paired observations.

In analysis of inter-rater agreement across all 198 available paired ratings, weighted kappa coefficients ranged from .44 (consolability) to.76 (respiratory drive/response to ventilation) across the 7 dimension ratings, indicating moderate to good inter-rater agreement (see Table 2).[33] This conclusion was additionally supported by weighted kappas generated from analysis of data which included only the first rating for each patient (range .55 to .77), and of a randomly-selected single rating for each patient (range .54 to .74, data not shown). The actual concordance rates for the 7 SBS dimensions (percent of ratings where the two raters gave the exact same rating), using all 198 available ratings, ranged from 66\% (tolerance to care) to $85 \%$ (respiratory drive/response to ventilation) (data not shown).

Similarly, inter-rater agreement for the NRS rating was good, with an ICC of .79 across all 198 paired ratings, .83 using only data from the first ratings, and .79 using randomly-selected single ratings.

The level of inter-rater agreement did not differ by patient age group, except for the coughing dimension. In analyses of all 198 paired ratings, the weighted kappa for this dimension was significantly lower in the youngest age group of 6 weeks to 1 year $(.55,95 \%$ CI $.41-.69)$, compared to the weighted kappa in the oldest age group of 3 to 6 years $(.81,95 \%$ CI .68-.93). The middle age group, ages 1 to 3 years, had a weighted kappa of .73 (95\% CI .68-.93).

In Table 2, we show the state behavioral profiles of the 5 groups identified from cluster analysis. We present the results of analysis of all 198 ratings which did not differ from those of 91 randomly selected single patient ratings. Also, since inter-rater agreement was generally good for the paired dimension ratings, we are presenting the results of cluster analysis using averaged data for the rater pairs. As shown by the median scores on each of the 7 dimensions, and mean NRS ratings, these 5 groups had distinct profiles of scores. Specifically, these cluster groups had significantly different mean scores on the NRS (one-way ANOVA F $=75.8, \mathrm{df}=4, \mathrm{p}<0.001$ ), with each group differing from all other groups in post-hoc pairwise comparisons (all $\mathrm{p}<.002$ ), supporting the discriminant validity of these 5 profiles.

Using the median scores on the 7 dimensions and mean NRS scores for each group (see Table 2 ), the 5 profiles were then aligned to a bipolar numeric scale ranging from -3 to +1 . We selected this metric because our group had experience using a modified MAAS [27] with a bipolar scale that clinicians described as logical and readily recalled; specifically, negative numbers equated to a less active states and more positive numbers equated to more active states. This bipolar numeric rating scale was also used in the original Sedation-Agitation Scale for critically ill adults. [26] The first cluster group with a mean (95\% CI) NRS score of 1.1 (0.71.6) was linked to a SBS dimension of -3 while the fourth cluster group with a mean NRS score of 5.3 (4.9-5.6) was equated with a SBS dimension of 0 . The remaining $-2,-1$ and +1 values were then aligned around these fixed points.

Table 3 presents the empirically generated pediatric State Behavioral Scale (SBS) with standardized definitions given for each point on the scale, similar to those used in the adult MAAS. [27] We also added a +2 agitated level because, though rarely observed thus not empirically captured in this study, experienced clinicians have cared for patients exhibiting these agitated behaviors in the pediatric ICU. 


\section{DISCUSSION}

We empirically constructed a standardized State Behavioral Scale (SBS) to describe the sedation-agitation continuum in an extremely vulnerable patient sample of young pediatric patients supported on mechanical ventilation. The SBS was derived from ratings of 7 content dimensions (originally 8 , but 2 dimensions were combined) derived from the literature and expert opinion and we describe adequate content validity and interrater reliability of these dimensions. An ideal sedation scale for pediatric intensive care should be valid and reliable, developmentally appropriate, integrate the multidimensional goals of sedation, be easy to complete and interpret, contain precise discriminating criteria at each level, and be useful in directing sedative therapy. [34-36] We believe the SBS meets these criteria.

The SBS was specifically designed for and tested in young intubated mechanically ventilated patients - a population who often experience extremes in level of sedation over their normal trajectory of illness. The tool reflects the presence and severity of the clinical conditions for which sedation is administered in this population. [20,36] We designed the SBS to require an evaluation of patient response to a progressive stimulus. This approach is familiar to intensive care clinicians as it is similar to the progressive stimulus performed during a neurological exam. We believe that appropriate levels of sedation should help the young patient through necessary care procedures that require a stimulated state while avoiding over-sedation when not stimulated.

The dimensions include descriptors that have been previously described to be associated with agitation. [24] More negative scores reflect a more sedated state. More positive scores reflect a more agitated state. The single-digit bipolar numeric avoids the complexity of summing multiple dimension scores and is logical in that the use of negative numbers for sedation and positive number for agitation and zero score for neither sedation nor agitation may enhance clinician recall of the measure. Each level contains multiple descriptors increasing the likelihood that a patient's behavior can be mapped to a single level. The SBS was developed to augment a clinician's clinical judgment. Differentiating behavioral distress from physiologic distress requires the clinician to interpret patient behavior within the context of their evolving clinical state.

Although the ease with which the nurse evaluators rated each dimension was not systemically described, the overall experience of the raters was that the dimensions were clear and that completion of the behavioral assessment tool and NRS was easily accomplished in less than two minutes after the stimulation protocol was implemented. However, some dimensions may be more challenging to rate than others, for example, a patient may console differently to a nurse's voice/touch and to a known caregiver's voice/touch. The relatively low weighted kappa reported for consolability may also be in part due to a sensitivity of the kappa to the response distribution, which in the case of this item, was highly skewed. Over $95 \%$ of ratings by either rater consisted of "self-regulates" or "able to calm; distractible," with only $4 \%$ giving a rating of "does not consistently calm" or "unable to console." The actual concordance rate between raters for this item was moderately high, at 69\% among all 198 ratings (79\% among first ratings, $74 \%$ among randomly-selected single ratings), indicating inter-rater agreement comparable to the other dimensions.

Except for the coughing dimension, the level of inter-rater agreement did not differ by patient age group. The weighted kappa for coughing was significantly lower in the youngest age group ( 6 weeks to 1 year) compared to the weighted kappa in the oldest age group ( 3 to 6 years). It should be noted that coughing was the only dimension that was not always directly observed. We are unable to determine in this study whether coughing is a more salient dimension for certain age groups compared to others, thus affecting inter-rater agreement across the age 
groups. However, inter-rater agreement of the coughing dimension may become more consistent across age groups when bedside nurses directly observe the phenomenon. Future studies evaluating the new SBS tool should assess the ease/difficulty in which the rating is made.

It is not surprising that an extreme agitated state was not well observed in this patient sample. While these behaviors do occur, we hypothesize that nurses immediately intervene to manage evolving unsafe and inconsolable behaviors in young intubated mechanically ventilated patients. Our findings are similar to those of Sessler et al [37] who validated the Richmond Agitation-Sedation Scale (RASS) in a wide distribution of critically-ill adult patients. The RASS ranges from -5 (unresponsive) to +4 (combative). Only $10 \%$ of their observations were in the +1 restless to +3 very agitated range and none were noted to be +4 combative.

We recommended that sedation assessment be completed at the start of normal cares at a frequency that aligns with the patient's clinical state. The Joint Commission for the Accreditation of Hospitals suggests that pain scoring be considered the $5^{\text {th }}$ vital sign. [38] We suggest that sedation scoring should be completed with the patient's pain assessment every four hours and also before and after an intervention that impacts the patient's level of sedation.

The use of a convenience sample was a limitation of this study and may reduce the generalizability of our findings. Data collection required the presence of two trained observers which precluded consecutive sampling. Data collection also did not alter current practice and/ or the administration of sedatives; thus, few patients exhibited an agitated state. Specifically, seven patients accounted for a total of eight $+1 /+2$ SBS ratings (one patient accounted for two ratings). Our data indicated that nurses were successful in keeping their patients in a more sedated state while intubated. Towards the end of the data collection period, we attempted to identify more awake patients by focusing on the enrollment of patients just before endotracheal extubation. Next, although we excluded patients assessed to be in pain we cannot be completely certain that these developmentally nonverbal or verbal intubated patients were pain-free. Pain and sedation scoring require clinical judgment and an evaluation of the context of patient trajectory and history. Future studies should test the construct validity of this instrument compared with a valid and reliable pain tool. Future studies should also assess the sensitivity of the SBS to assess a change in a patient's state over time or after sedative administration to determine its usefulness in informing patient-specific alterations in the therapeutic regimen and to describe the effect of illness/injury on the patient's state behavior. Finally, since the SBS tool was developed using ratings of patients ages 6 weeks to 6 years who were physiologically stable and not rated to be in pain, other studies are needed to assess the appropriateness of this tool for use in populations not included in this study. Additional studies are also needed, using much larger samples, to assess the validity of the SBS profiles within each of the three pediatric age groups included in this study. While we had equal representation of the three age groups in our sample, we had too few observations in the agitated range to be able to conduct cluster analyses stratified by age group.

In summary, of primary concern to all clinicians caring for critically ill pediatric patients is to limit the negative impact of the illness on the developing child. Many factors contribute to the process of providing this humanistic element of care, one of which includes assuring an adequate level of sedation. We believe that the PICU environment taxes the adaptive capacities of even our most resilient patients and that our preverbal patients are at a particular disadvantage as they are cognitively immature to process the importance of tolerance to invasive procedures, instrumentation and support. The State Behavioral Scale describes the sedation-agitation continuum in this vulnerable group. 


\section{Acknowledgements}

We are indebted to the pediatric critical care nurses and our patients and their families who supported this study, David Wypij, PhD who provided comments early in the design of the study; and Michelle Labrecque, MSN, RN and Patricia Jones MSN, RN who assisted with patient screening and data collection.

\section{References}

1. Gordin PC. Assessing and managing agitation in a critically ill infant. MCN Am J Matern Child Nurs 1990;15(1):26-32. [PubMed: 2105425]

2. Marx CM, Rosenberg DI, Ambuel B, Hamlett KW, Blumer JL. Pediatric intensive care sedation: survey of fellowship training programs. Pediatrics 1993;91(2):369-378. [PubMed: 8424013]

3. Durbin CG. Sedation in the critically ill patient. New Horiz 1994;2(1):64-74. [PubMed: 7922431]

4. Chevron V, Menard JF, Richard JC, Girault C, Leroy J, Bonmarchand G. Unplanned extubation: risk factors of development and predictive criteria for reintubation. Crit Care Med 1998;26(6):1049-1053. [PubMed: 9635654]

5. Kollef MH, Levy NT, Ahrens TS, Schaiff R, Prentice D, Sherman G. The use of continuous i.v sedation is associated with prolongation of mechanical ventilation. Chest 1998;114(2):541-548. [PubMed: 9726743]

6. Fonsmark L, Rasmussen YH, Carl P. Occurrence of withdrawal in critically ill sedated children. Crit Care Med 1999;27(1):196-199. [PubMed: 9934916]

7. Randolph AG, Wypij D, Venkataraman ST, Hanson JH, Gedeit RG, Meert KL, Luckett PM, Forbes P, Lilley M, Thompson J, et al. Effect of mechanical ventilator weaning protocols on respiratory outcomes in infants and children: a randomized controlled trial. Jama 2002;288(20):2561-1568. [PubMed: 12444863]

8. Playfor SD, Thomas DA. Quality of sedation during mechanical ventilation. Paediatric Anasethsia 2000;10(2):195-199.

9. Young C, Knudsen N, Hilton A, Reves JG. Sedation in the intensive care unit. Critical Care Medicine 2000;28(3):854-866. [PubMed: 10752842]

10. Simmons LE, Riker RR, Prato BS, Fraser GL. Assessing sedation during intensive care unit mechanical ventilation with the Bispectral Index and the Sedation-Agitation Scale. Crit Care Med 1999;27(8):1499-1504. [PubMed: 10470756]

11. Westcott $\mathrm{C}$. The sedation of patients in intensive care units: a nursing review. Intensive \& Critical Care Nursing 1995;11(1):26-31.

12. Twite MD, Rashid A, Zuk J, Friesen RH. Sedation, analgesia, and neuromuscular blockade in the pediatric intensive care unit: survey of fellowship training programs. [see comment]. Pediatr Crit Care Med 2004;5(6):521-532. [PubMed: 15530187]

13. Hansen-Flaschen JH, Brazinsky S, Basile C, Lanken PN. Use of sedating drugs and neuromuscular blocking agents in patients requiring mechanical ventilation for respiratory failure. A national survey. Jama 1991;266(20):2870-2875. [PubMed: 1942456]

14. Marx CM, Smith PG, Lowrie LH, Hamlett KW, Ambuel B, Yamashita TS, Blumer JL. Optimal sedation of mechanically ventilated pediatric critical care patients. Crit Care Med 1994;22(1):163170. [PubMed: 8124960]

15. Bair N, Bobek MB, Hoffman-Hogg L, Mion LC, Slomka J, Arroliga AC. Introduction of sedative, analgesic, and neuromuscular blocking agent guidelines in a medical intensive care unit: physician and nurse adherence. Crit Care Med 2000;28(3):707-713. [PubMed: 10752819]

16. Brook AD, Ahrens TS, Schaiff R, Prentice D, Sherman G, Shannon W, Kollef MH. Effect of a nursingimplemented sedation protocol on the duration of mechanical ventilation. Crit Care Med 1999;27 (12):2609-2615. [PubMed: 10628598]

17. Kress JP, Pohlman AS, O'Connor MF, Hall JB. Daily interruption of sedative infusions in critically ill patients undergoing mechanical ventilation. [see comment]. N Engl J Med 2000;342(20):14711477. [PubMed: 10816184]

18. Ostermann ME, Keenan SP, Seiferling RA, Sibbald WJ. Sedation in the intensive care unit: a systematic review. Jama 2000;283(11):1451-1459. [PubMed: 10732935] 
19. Ramsay MA, Savege TM, Simpson BR, Goodwin R. Controlled sedation with alphaxalonealphadolone. British Medical Journal 1974;2(920):656-659. [PubMed: 4835444]

20. Hansen-Flaschen JH, Cowen J, Polomano RC. Beyond the Ramsay scale: Need for a validated measure of sedating drug efficicy in the intensive care unit. Crit Care Med 1994;22(5):732-733. [PubMed: 8181279]

21. Ambuel B, Hamlett KW, Marx CM, Blumer JL. Assessing distress in pediatric intensive care environments: the COMFORT scale. J Pediatr Psychol 1992;17(1):95-109. [PubMed: 1545324]

22. van Dijk M, de Boer JB, Koot HM, Tibboel D, Passchier J, Duivenvoorden HJ. The reliability and validity of the COMFORT scale as a postoperative pain instrument in 0 to 3 -year-old infants. Pain 2000;84(2-3):367-377. [PubMed: 10666543]

23. Wansbrough SR, White PF. Sedation scales: measures of calmness or somnolence? Anesthesia \& Analgesia 1993;76(2):219-221. [PubMed: 8424494]

24. Curley M, McDermott B, Berry P, Hurley J, MacKey C, McAleer D, Alsip C. Nurses desicion making regarding the use of analgesics and sedatives in the pediatric ICU. Heart \& Lung 1992;21(3):296.

25. Riker RR, Picard JT, Fraser GL. Prospective evaluation of the Sedation-Agitation Scale for adult critically ill patients. Crit Care Med 1999;27(7):1325-1329. [PubMed: 10446827]

26. Riker RR, Fraser GL, Cox PM. Continuous infusion of haloperidol controls agitation in critically ill patients. Crit Care Med 1994;22(3):433-440. [PubMed: 8124994]

27. Devlin JW, Boleski G, Mlynarek M, Nerenz DR, Peterson E, Jankowski M, Horst HM, Zarowitz BJ. Motor Activity Assessment Scale: a valid and reliable sedation scale for use with mechanically ventilated patients in an adult surgical intensive care unit. Crit Care Med 1999;27(7):1271-1275. [PubMed: 10446819]

28. Clemmer TP, Wallace JC, Spuhler VJ, Bailey PP, Devlin JW. Origins of the Motor Activity Assessment Scale score: a multi-institutional process. Crit Care Med 2000;28(8):3124. [PubMed: 10966328]

29. Carnevale FARNP, Razack SMD. An item analysis of the COMFORT scale in a pediatric intensive care unit. Pediatr Crit Care Med 2002;3(2):177-180. [PubMed: 12780990]

30. Fiser DH. Assessing the outcome of pediatric intensive care. J Pediatr 1992;121(1):68-74. [PubMed: 1625096]

31. Pollack MM, Patel KM, Ruttimann UE. The pediatric risk of mortality III-- Acute physiology score (PRISM III-APS): A method of assessing physiologic instability for pediatric intensive care unit patients. J Pediatr 1997;131(4):575-581. [PubMed: 9386662]

32. Cohen J. Weighted kappa: Nominal scale agreement with provision for scaled disagreement or partial credit. Psychological Bulletin 1968;70:213-220.

33. Landis JR, Koch GG. The measurement of observer agreement for categorical data. Biometrics 1977;33:159-174. [PubMed: 843571]

34. De Jonghe B, Cook D, Appere-de-Vecchi C, Guyatt G, Meade M, Outin H. Using and understanding sedation scoring systems: A systematic review. Intensive Care Med 2000;26 :275-285. [PubMed: 10823383]

35. Chulay M. Sedation assessment: easier said then done! Crit Care Nurs Clin N Am 2004;16 :359-364.

36. Lieberman J, Tremper KK. Sedation: if you do not know where you are going, any road will get you there. Crit Care Med 1999;27(7):1395-1396. [PubMed: 10446845]

37. Sessler CN, Gosnell MS, Grap MJ, Brophy GM, O'Neal PV, Keane KA, Tesoro EP, Elswick RK. The Richmond Agitation-Sedation Scale: validity and reliability in adult intensive care unit patients. Am J Respir Crit Care Med 2002;166(10):1338-1344. [PubMed: 12421743]

38. Kerns, RD.; Wasse, L.; Ryan, B. Pain as the 5th Vital Sign Toolkit. V2. Washington, DC: Veterans Health Administration; 2000. 


\begin{tabular}{|c|c|}
\hline Dimensions & Levels \\
\hline Respiratory Drive & $\begin{array}{ll}\text { 1. } & \text { No spontaneous respiratory effort } \\
\text { 2. } & \text { Spontaneous but ineffective exhaled tidal volume (Patient specific: }<4 \mathrm{cc} / \mathrm{kg} \text { ) } \\
\text { 3. } & \text { Spontaneous and effective exhaled tidal volume (Patient specific: }>4 \mathrm{cc} / \mathrm{kg} \text { ) }\end{array}$ \\
\hline $\begin{array}{l}\text { Response to } \\
\text { Ventilation }\end{array}$ & $\begin{array}{ll}\text { 1. No spontaneous breathing } \\
\text { 2. Easy spontaneous breathing (fully synchronized with mechanical ventilation) } \\
\text { 3. Having difficulty synchronizing with ventilator } \\
\text { 4. Unsynchronized with mechanical ventilation, compromising oxygenation/ventilation }\end{array}$ \\
\hline Coughing & $\begin{array}{l}\text { 1. No cough with suction } \\
\text { 2. Coughs only when suctioned } \\
\text { 3. Coughs when repositioned } \\
\text { 4. Occasional spontaneous cough } \\
\text { 5. Frequent spontaneous coughing that does not resolve with suctioning } \\
\text { 6. Bronchospastic or choking }\end{array}$ \\
\hline $\begin{array}{l}\text { Best Response } \\
\text { to Stimulation }\end{array}$ & $\begin{array}{ll}\text { 1. } & \text { No response to noxious stimuli } \\
\text { 2. } & \text { Responds to noxious stimulus } \\
\text { 3. } & \text { Responds to touch } \\
\text { 4. } & \text { Responds to voice } \\
\text { 5. } & \text { No external stimulus is required to elicit response }\end{array}$ \\
\hline $\begin{array}{l}\text { Attentiveness } \\
\text { to Care Provider }\end{array}$ & $\begin{array}{l}\text { 1. Unable to pay attention to care provider } \\
\text { 2. Able to pay attention to care provider but drifts off after stimulation } \\
\text { 3. Spontaneously pays attention to care provider (Infant - fixes and follows) } \\
\text { 4. Vigilant of care provider/Eyes follow care provider - watchful } \\
\text { 5. Hyper-vigilant to care provider/Panicky when care providers approach patient }\end{array}$ \\
\hline Tolerance to Care & $\begin{array}{l}\text { 1. Does not distress with any procedure including noxious } \\
\text { 2. Will distress with noxious procedures } \\
\text { 3. Distresses with procedures (i.e., repositioning) } \\
\text { 4. Distressed (e.g., picking at tubes, pulling at restraints, etc.) } \\
\text { 5. Patient intermittently unsafe (e.g., biting ETT) } \\
\text { 6. Patient unsafe (e.g., attempting to pull at ETT/catheters, cannot be left alone) }\end{array}$ \\
\hline Consolability & $\begin{array}{l}\text { 1. Self-regulates/modulates own behavior } \\
\text { 2. Able to calm with comforting touch or voice when stimulus removed; distractible } \\
\text { 3. Does not consistently calm despite a 5-minute attempt to console } \\
\text { 4. Unable to console }\end{array}$ \\
\hline $\begin{array}{l}\text { Movement after } \\
\text { Consoled }\end{array}$ & $\begin{array}{l}\text { 1. Does not move } \\
\text { 2. Occasional movement of extremities or shifting of position in bed } \\
\text { 3. Increased movement (restless, squirming) } \\
\text { 4. Excessive movement (thrashing side to side, kicking legs, arched, rigid) } \\
\text { 5. Combative }\end{array}$ \\
\hline
\end{tabular}

NRS:

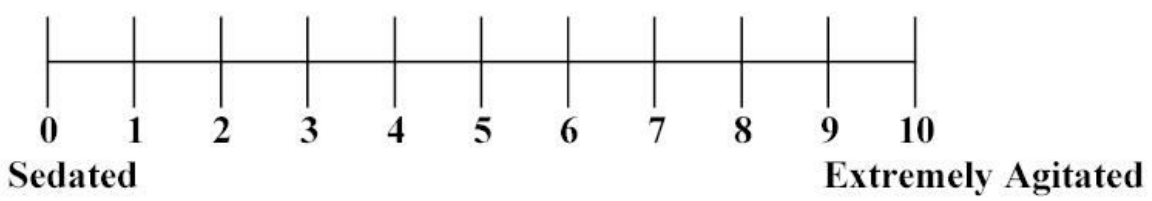

Figure 1.

Behavioral Assessment Tool and Numeric Rating Scale 


\section{Table 1}

Patient Demographics

(N=91)

\begin{tabular}{|c|c|}
\hline Characteristic & $(\mathrm{N}=91)$ \\
\hline Age (months) & $18(4.4-34.5)$ \\
\hline \multicolumn{2}{|l|}{ Age group No. (\%) } \\
\hline 6 weeks to 1 year & $38(42 \%)$ \\
\hline 1 to 3 years & $31(34 \%)$ \\
\hline 3 to 6 years & $22(24 \%)$ \\
\hline Female sex No. $(\%)$ & $34(37 \%)$ \\
\hline \multicolumn{2}{|l|}{ Race or ethnic group No. (\%) } \\
\hline White & $63(69 \%)$ \\
\hline Black & $4(4 \%)$ \\
\hline Hispanic & $11(12 \%)$ \\
\hline Asian/Pacific Islander & $3(3 \%)$ \\
\hline More than one group & $10(11 \%)$ \\
\hline Pediatric Cerebral Performance Category & $1(1,2)$ \\
\hline Pediatric Overall Performance Category $\$$ & $1(1,3)$ \\
\hline Pediatric Risk of Mortality III scores & $6(0-12)$ \\
\hline Mortality & $12(13 \%)$ \\
\hline \multicolumn{2}{|l|}{ Primary Diagnosis No. $(\%)$} \\
\hline Pulmonary & $46(51 \%)$ \\
\hline Cardiovascular & $12(13 \%)$ \\
\hline Neurological & $9(10 \%)$ \\
\hline Infectious disease/Sepsis & $6(7 \%)$ \\
\hline Congenital anomaly & $6(7 \%)$ \\
\hline Gastrointestinal & $5(6 \%)$ \\
\hline Oncology/Bone Marrow Transplant & $5(6 \%)$ \\
\hline Metabolic/trauma & $2(2 \%)$ \\
\hline Secondary Diagnoses No. (\%) & $45(49 \%)$ \\
\hline
\end{tabular}

Values with parentheses are number (percentage) or medians (first quartile, third quartile). Because of rounding, percentages may not total 100.

* Pediatric Cerebral Performance Category score ranges from 1 (normal cognitive development) to 6 (brain death). [30]

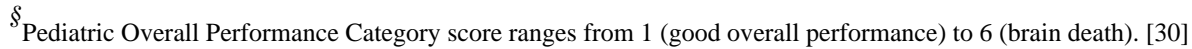

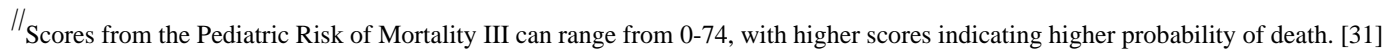


Table 2

Median score (interquartile range) on each State Behavior Scale (SBS) dimension and mean (95\%CI) numeric rating scale score (NRS), within each of 5 rating groups generated from cluster analysis using all ratings $(\mathrm{N}=198)$. Inter-rater reliability coefficients (weighted kappa and intra-class correlation [ICC]) for each SBS dimension and NRS using all ratings, and using only the first rating per patient $(\mathrm{n}=91)$.

\begin{tabular}{|c|c|c|c|c|c|c|c|}
\hline SBS Dimension & $\begin{array}{c}-3(n=33) \\
\text { Median (IQ } \\
\text { range) }\end{array}$ & $\begin{array}{c}-2(n=72) \\
\text { Median (IQ } \\
\text { range) }\end{array}$ & $\begin{array}{c}-1(n=26) \\
\text { Median (IQ } \\
\text { range) }\end{array}$ & $\begin{array}{c}0(n=59) \\
\text { Median (IQ } \\
\text { range) }\end{array}$ & $\begin{array}{c}+1 /+2(n=8) \\
\text { Median (IQ } \\
\text { range) }\end{array}$ & $\begin{array}{l}\text { Weighted } \\
\text { Kappa } \\
\text { ALL } \\
(95 \% \text { CI })\end{array}$ & $\begin{array}{l}\text { Weighted } \\
\text { Kappa } \\
\text { FIRST } \\
(95 \% \text { CI })\end{array}$ \\
\hline $\begin{array}{l}\text { Respiratory Drive/ } \\
\text { Response to ventilation }\end{array}$ & $\begin{array}{c}\text { No } \\
\text { spontaneous } \\
\text { respiratory } \\
\text { effort } \\
1.0(1.0- \\
1.5)\end{array}$ & $\begin{array}{c}\text { Spontaneous } \\
\text { and } \\
\text { effectively } \\
\text { supported } \\
\text { breathing } \\
3.0(3.0-3.0)\end{array}$ & $\begin{array}{c}\text { Spontaneous } \\
\text { but } \\
\text { ineffective/ } \\
\text { effectively } \\
\text { supported } \\
\text { breathing } \\
2.8(1.9-3.0)\end{array}$ & $\begin{array}{l}\text { Spontaneous } \\
\text { and effective } \\
\text { breathing } \\
3.0(3.0-3.0)\end{array}$ & $\begin{array}{l}\text { Spontaneous } \\
\text { and effective/ } \\
\text { Having } \\
\text { difficulty } \\
\text { synchronizing } \\
\text { with ventilator } \\
3.0(3.0-3.9)\end{array}$ & $\begin{array}{c}.76(.67- \\
84)\end{array}$ & $\begin{array}{c}.77(.65-. \\
88)\end{array}$ \\
\hline Coughing & $\begin{array}{l}\text { No cough/ } \\
\text { coughs only } \\
\text { when } \\
\text { suctioned } \\
2.0(1.0- \\
2.0)\end{array}$ & $\begin{array}{l}\text { Coughs only } \\
\text { when } \\
\text { suctioned pr } \\
\text { when } \\
\text { repositioned } \\
3.0(2.0-3.9)\end{array}$ & $\begin{array}{l}\text { Coughs only } \\
\text { when } \\
\text { suctioned or } \\
\text { when } \\
\text { repositioned } \\
2.0(2.0-3.0)\end{array}$ & $\begin{array}{l}\text { Coughs when } \\
\text { repositioned/ } \\
\text { Occasional } \\
\text { spontaneous } \\
\text { cough } \\
3.5(3.0-4.0)\end{array}$ & $\begin{array}{c}\text { Occasional } \\
\text { spontaneous } \\
\text { cough } \\
4.0(4.0-4.0)\end{array}$ & $\begin{array}{c}.68(.59- \\
77)\end{array}$ & $\begin{array}{c}.76(.64-. \\
87)\end{array}$ \\
\hline $\begin{array}{l}\text { Best Response to } \\
\text { Stimulation }\end{array}$ & $\begin{array}{l}\text { No response } \\
\text { to noxious } \\
\text { stimuli } \\
1.0(1.0- \\
2.0)\end{array}$ & $\begin{array}{l}\text { Responds to } \\
\text { noxious } \\
\text { stimuli/ } \\
\text { touch } \\
2.0(1.6-3.0)\end{array}$ & $\begin{array}{l}\text { Respond to } \\
\text { touch/voice } \\
3.5(3.0-4.0)\end{array}$ & $\begin{array}{l}\text { Responds to } \\
\text { voice/No } \\
\text { external } \\
\text { stimulus } \\
\text { required to } \\
\text { elicit response } \\
4.5(4.0-5.0)\end{array}$ & $\begin{array}{l}\text { Responds to } \\
\text { voice/No } \\
\text { external } \\
\text { stimulus } \\
\text { required to } \\
\text { elicit response } \\
4.8(3.6-5.0)\end{array}$ & $\begin{array}{c}.71(.64- \\
78)\end{array}$ & $\begin{array}{c}.65(.54-. \\
76)\end{array}$ \\
\hline $\begin{array}{l}\text { Attentiveness to Care } \\
\text { Provider }\end{array}$ & $\begin{array}{c}\text { Unable to } \\
\text { pay } \\
\text { attention to } \\
\text { care } \\
\text { provider } \\
1.0(1.0- \\
1.0)\end{array}$ & $\begin{array}{l}\text { Unable to } \\
\text { pay attention } \\
\text { to care } \\
\text { provider } \\
1.0(1.0-1.0)\end{array}$ & $\begin{array}{l}\text { Able to pay } \\
\text { attention to } \\
\text { care } \\
\text { provider but } \\
\text { drifts off } \\
\text { after } \\
\text { stimulation } \\
1.5(1.0-2.0)\end{array}$ & $\begin{array}{l}\text { Spontaneously } \\
\text { pays attention } \\
\text { to care } \\
\text { provider } \\
\text { (infant fixes } \\
\text { and follows) } \\
3.0(2.5-3.0)\end{array}$ & $\begin{array}{c}\text { Drifts off/ } \\
\text { Spontaneously } \\
\text { pays attention } \\
2.5(1.8-2.5)\end{array}$ & $\begin{array}{l}.69(.61-. \\
76)\end{array}$ & $\begin{array}{c}.67(.56-. \\
78)\end{array}$ \\
\hline Tolerance to Care & $\begin{array}{c}\text { Does not } \\
\text { distress with } \\
\text { any } \\
\text { procedure } \\
\text { (including } \\
\text { noxious) } \\
1.0(1.0- \\
1.0)\end{array}$ & $\begin{array}{c}\text { Will distress } \\
\text { with noxious } \\
\text { procedure } \\
1.5(1.0-2.0)\end{array}$ & $\begin{array}{c}\text { Distresses } \\
\text { with } \\
\text { procedures } \\
2.5(2.0-3.0)\end{array}$ & $\begin{array}{c}\text { Distresses } \\
\text { with } \\
\text { procedures } \\
2.5(2.0-3.0)\end{array}$ & $\begin{array}{c}\text { Intermittently } \\
\text { unsafe } \\
4.5(4.0-5.0)\end{array}$ & $\begin{array}{c}.63(.55-. \\
71)\end{array}$ & $\begin{array}{c}.60(.48- \\
73)\end{array}$ \\
\hline Consolability & $\begin{array}{c}\text { Self- } \\
\text { regulates/ } \\
\text { modulates } \\
\text { own } \\
\text { behavior } \\
1.0(1.0- \\
1.0)\end{array}$ & $\begin{array}{c}\text { Self- } \\
\text { regulates/ } \\
\text { modulates } \\
\text { own } \\
\text { behavior } \\
1.0(1.0-1.0)\end{array}$ & $\begin{array}{l}\text { Able to calm } \\
\text { with } \\
\text { comforting } \\
\text { touch or } \\
\text { voice when } \\
\text { stimulus } \\
\text { removed } \\
1.5(1.5-2.0)\end{array}$ & $\begin{array}{l}\text { Able to calm } \\
\quad \text { with } \\
\text { comforting } \\
\text { touch or voice } \\
\text { when stimulus } \\
\text { removed } \\
2.0(1.5-2.0)\end{array}$ & $\begin{array}{c}\text { Does not } \\
\text { consistently } \\
\text { calm despite } 5 \\
\text { minute } \\
\text { attempt to } \\
\text { console } \\
2.8(2.5-3.4)\end{array}$ & $\begin{array}{l}.44(.32- \\
55)\end{array}$ & $\begin{array}{c}.62(.46- \\
77)\end{array}$ \\
\hline Movement after Consoled & $\begin{array}{c}\text { Does not } \\
\text { move } \\
1.0(1.0- \\
1.0)\end{array}$ & $\begin{array}{c}\text { Does not } \\
\text { move/ } \\
\text { Occasional } \\
\text { movement } \\
\text { of } \\
\text { extremities } \\
\text { or shifting of } \\
\text { position } \\
1.0(1.0-1.5)\end{array}$ & $\begin{array}{l}\text { Occasional } \\
\text { movement } \\
\text { of } \\
\text { extremities } \\
\text { or shifting of } \\
\text { position } \\
2.0(2.0-2.0)\end{array}$ & $\begin{array}{c}\text { Occasional } \\
\text { movement/ } \\
\text { Increased } \\
\text { movement } \\
\text { (restless, } \\
\text { squirming) } \\
2.0(2.0-2.5)\end{array}$ & $\begin{array}{l}\text { Increased } \\
\text { movement } \\
\text { (restless, } \\
\text { squirming) } \\
3.0(2.6-3.0)\end{array}$ & $\begin{array}{c}.61(.52- \\
70)\end{array}$ & $\begin{array}{c}.55(.43- \\
68)\end{array}$ \\
\hline Mean NRS (95\%CI) & $\begin{array}{c}1.1(0.7- \\
1.6)\end{array}$ & $2.5(2.1-2.9)$ & $4.0(3.4-4.5)$ & $5.3(4.9-5.6)$ & $7.6(6.9-8.4)$ & $\begin{array}{c}\text { ICC }=. \\
79(.73-. \\
84)\end{array}$ & $\begin{array}{l}\text { ICC }=\text {. } \\
83(.76-. \\
89)\end{array}$ \\
\hline
\end{tabular}


State Behavioral Scale (SBS)

Table 3

Score as patient's response to voice then gentle touch then noxious stimuli (planned endotracheal suctioning or $<5$ seconds of nail bed pressure)

\begin{tabular}{|c|c|c|}
\hline Score & Description & Definition \\
\hline-3 & Unresponsive & $\begin{array}{l}\text { No spontaneous respiratory effort } \\
\text { No cough or coughs only with suctioning } \\
\text { No response to noxious stimuli } \\
\text { Unable to pay attention to care provider } \\
\text { Does not distress with any procedure (including noxious) } \\
\text { Does not move }\end{array}$ \\
\hline-2 & $\begin{array}{l}\text { Responsive to noxious } \\
\text { stimuli }\end{array}$ & $\begin{array}{l}\text { Spontaneous yet supported breathing } \\
\text { Coughs with suctioning/repositioning } \\
\text { Responds to noxious stimuli } \\
\text { Unable to pay attention to care provider } \\
\text { Will distress with a noxious procedure } \\
\text { Does not move/occasional movement of extremities or shifting of position }\end{array}$ \\
\hline-1 & $\begin{array}{l}\text { Responsive to gentle } \\
\text { touch or voice }\end{array}$ & $\begin{array}{l}\text { Spontaneous but ineffective nonsupported breaths } \\
\text { Coughs with suctioning/repositioning } \\
\text { Responds to touch/voice } \\
\text { Able to pay attention but drifts off after stimulation } \\
\text { Distresses with procedures } \\
\text { Able to calm with comforting touch or voice when stimulus removed } \\
\text { Occasional movement of extremities or shifting of position }\end{array}$ \\
\hline 0 & $\begin{array}{l}\text { Awake and able to } \\
\text { calm }\end{array}$ & $\begin{array}{l}\text { Spontaneous and effective breathing } \\
\text { Coughs when repositioned/Occasional spontaneous cough } \\
\text { Responds to voice/No external stimulus is required to elicit response } \\
\text { Spontaneously pays attention to care provider } \\
\text { Distresses with procedures } \\
\text { Able to calm with comforting touch or voice when stimulus removed } \\
\text { Occasional movement of extremities or shifting of position/increased movement (restless, squirming) }\end{array}$ \\
\hline+1 & $\begin{array}{l}\text { Restless and difficult to } \\
\text { calm }\end{array}$ & $\begin{array}{l}\text { Spontaneous effective breathing/Having difficulty breathing with ventilator } \\
\text { Occasional spontaneous cough } \\
\text { Responds to voice/No external stimulus is required to elicit response } \\
\text { Drifts off/Spontaneously pays attention to care provider } \\
\text { Intermittently unsafe } \\
\text { Does not consistently calm despite } 5 \text { minute attempt/unable to console } \\
\text { Increased movement (restless, squirming) }\end{array}$ \\
\hline+2 & Agitated & $\begin{array}{l}\text { May have difficulty breathing with ventilator } \\
\text { Coughing spontaneously } \\
\text { No external stimulus required to elicit response } \\
\text { Spontaneously pays attention to care provider } \\
\text { Unsafe (biting ETT, pulling at lines, cannot be left alone) } \\
\text { Unable to console } \\
\text { Increased movement (restless, squirming or thrashing side-to-side, kicking legs) }\end{array}$ \\
\hline
\end{tabular}

